\title{
Healthy Active Kids South Africa: How do we score?
}

The Healthy Active Kids South Africa (HAKSA) was initiated in 2007 by Prof. Vicki Lambert of the University of Cape Town, South Africa (SA). The idea arose after she attended an international conference on Physical Activity and Obesity in Children in Toronto, Canada, and witnessed the impact that the release of the Healthy Active Kids Canada Report Card had in that country. On her return, she garnered the support of nine enthusiastic scientists from six tertiary academic institutions in SA, convinced Discovery Vitality and the Sports Science Institute of $S A$ that it was a worthwhile project to support, and together they produced the first HAKSA Report Card. Although this created media interest, it did not really translate into concerted action. Undeterred, the group repeated the exercise in 2010 - this time, there were 18 academics representing 10 institutions and NGOs. The scope was widened to include peer-reviewed literature, dissertations and government reports. The uptake this time was more promising, and the focus of the report was directed more toward intersectoral policies and programmes to try to effect change. In 2014, as part of the Global Summit on Physical Activity and Children, the team repeated their efforts, this time with 21 scientists from 15 academic institutions and NGOs. The additional outcomes of the 2014 report included an advocacy document and a peer-reviewed manuscript. The impact of the report is also going to be evaluated.

There are many good stories coming out of this initiative. Firstly, SA is one of 15 countries around the world that has started evaluating the world in which our youth live. Five of the countries are from Africa. Secondly, it seems that the outcomes of this report have pressed the right buttons, with promising signs that national, regional and local government along with NGOs have taken note and are starting to talk about ways in which they can contribute to raise the overall rating (we slid from a C- in 2010 to a D grade in 2014).

The report has also exposed many causes for concern - all the members of the SA Sports Medicine Association (SASMA) should take note because many of these areas are covered by the varied scope of practice of SASMA members. For example, almost half the children studied are insufficiently active, getting $<1 \mathrm{~h} /$ day of physical activity. Sedentary behaviour remains a problem, with children spending just under $3 \mathrm{~h}$ /day watching television (we are nearly bottom of the list for this category compared with the other 14 countries). Overweight and obesity continue to increase, possibly linked to the fact that over two-thirds of adolescents consume fast foods at least three times per week. There is also a progressive increase in the consumption of sugarsweetened drinks.

However, it is not all doom and gloom. We achieved a high score (B) for the National School Nutrition Programme, where the reach has improved and more children are benefitting from the programme. We also scored a B for the category of government strategies and investments, where it is evident that programmes have been developed to increase physical activity among children through various policies and investments. It just may take some time to realise the benefits of these investments and programmes.

The report emphasises that much can be done to improve the health and wellbeing of our youth. Changes can be implemented at the level of the family, the community in which the child lives and in the school environment. The report has identified the weaker areas; now it is going to take creative thinking and a willingness to get involved to make a difference. Every health professional in the country should read the report; there is no doubt that after reading it there will be a heightened

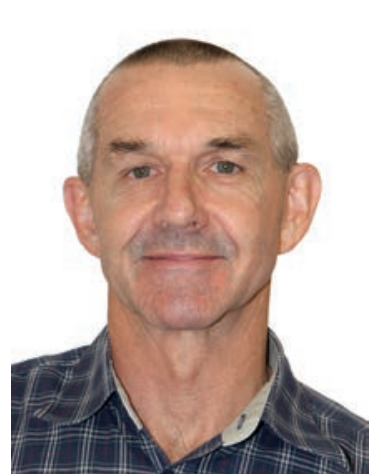
awareness of the problem areas. The challenge thereafter is to embrace a problem area and try to make a change - a small change made by everyone will have a much bigger impact than a large change made by a few. The full report can be viewed on the website of the Sports Science Institute of SA website (http://www.ssisa.com).

Mike Lambert

Editor-in-chief 